\title{
Effect of machining parameter on the surface roughness of AISI 304 in silicon carbide powder mixed EDM
}

\author{
Munmun Bhaumik $^{\mathrm{a}^{*}}$ and Kalipada Maity
}

\begin{tabular}{l} 
a. Department of Mechanical Engineering \\
\hline C H R O N I C L E \\
\hline Article history: \\
Received September 3, 2016 \\
Received in revised format: \\
October 22, 2016 \\
Accepted December 15, 2016 \\
Available online \\
December 15 2016 \\
\hline Keywords: \\
AISI 304 stainless steel \\
Powder mixed electro discharge \\
machining \\
Regression analysis \\
Surface roughness \\
Tungsten carbide
\end{tabular}

\section{Introduction}

Electric discharge machining (EDM) is the most popular among all the nonconventional machining process. Sometimes this type of machining is also called spark erosion machining because the material removed from the workpiece occurs by means of erosion attributed by electric spark (Choudhary et al., 2013). Conventional EDM has some advantages as well as some disadvantages. To overcome the disadvantages, the conventional EDM is replaced by hybrid EDM. Powder mixed electro discharge machining (PMEDM) is a popular hybrid EDM technique to enhance the material removal as well as the surface finish (Rajagopal et al., 2013; Pandey et al., 2010). Bhaumik and Maity (2014) investigated the effect of tungsten carbide electrode on the EDM performance while material removal rate (MRR), tool wear rate (TWR) and surface roughness $\left(\mathrm{R}_{\mathrm{a}}\right)$ are taken as responses during machining of AISI 304 stainless steel. Mohanty et al. (2014) studied the influence of process parameter on the various EDM

* Corresponding author

E-mail address: munmunbhaumik@gmail.com (M. Bhaumik)

(C) 2017 Growing Science Ltd. All rights reserved. doi: $10.5267 /$ j.dsl.2016.12.004 \begin{abstract}
A B S T R A C T
Powder mixed electro discharge machining (PMEDM) is a hybrid machining process where ender is suspended into a dielectric medium, for enhancing the (EDM) has been performed for the machining of AISI 304 stainless steel by using the tungsten carbide electrode, when silicon carbide $(\mathrm{SiC})$ powder is suspended into kerosene dielectric medium. Peak current, pulse on time, gap voltage, duty cycle and powder concentration are effect of significant process parameters on the response has been studied. A regression analysis has been performed to describe the correlation of data between the machining parameter, and the response. Microstructural analysis has been done for the PMEDMed surface. The result shows that peak current is the most influential parameter for surface roughness. Surface roughness decreases with the increase of powder concentration.
\end{abstract}

(C) 2017 Growing Science Ltd. All rights reserved. 
performances such as MRR, surface roughness (SR), radial overcut (ROC) and surface crack density (SCD) during machining of Inconel 625 and found that peak current was the most influencing parameter for all the performances. Pradhan (2013) determined the optimal setting for the machining of AISI D2 tool steel using the combination of response surface methodology (RSM) and grey relational analysis (GRA) coupled with principal component analysis (PCA) where they considered MRR, tool wear rate (TWR), ROC as response. Luis et al. (2005) studied the MRR and electrode wear (EW) for the siliconised or reaction-bonded silicon carbide ( $\mathrm{SiSiC}$ ) during electro discharge machining. Habib et al. (2009) developed mathematical model for the EDM performances viz. MRR, electrode wear ratio (EWR), gap size (GS), $\mathrm{R}_{\mathrm{a}}$ for metal matrix composite $\mathrm{Al} / \mathrm{SiC}$. For improving the process performance the semi conductive powder particles are suspended into the dielectric fluid during electro discharge machining (Kumar et al., 2010; Singh et al., 2011). Kansal et al. (2005, 2007) studied the machining performance of AISI D2 and EN31 steel when silicon powder was suspended in the kerosene dielectric and reported a significant improvement in terms of material removal and surface finish. Bhattacharya et al. (2013) studied the surface properties viz. surface finish and microhardness of die steel using PMEDM. They used graphite, silicon and tungsten powder for this investigation and reported that microhardness and surface finish both are affected by the powder concentration. Kumar and Batra (2012) reported the material transfer during EDM for die steels (OHNS die steel, H13 die steel and D2 die steel) when tungsten carbide powder are added in the dielectric fluid. They concluded that the significant amount of material migrated from the dielectric medium to the work material. Singh et al. (2015) have investigated the enhancement of material removal rate when tungsten powder added into the kerosene dielectric during machining of aluminum alloy $6061 / 10 \% \mathrm{SiC}$ composite in electro discharge machining. They reported that material removal was enhanced by $48.43 \%$ during PMEDM.

From the above literature, it is evident that most of the researchers have reported about the enhancement of material removal and surface characteristics of the EDMed surface. In this present investigation, a face centered central composite design (FCCCD) based response surface methodology (RSM) has been adopted to design the experimental layout. $\mathrm{SiC}$ powder is mixed in the kerosene dielectric for the machining of AISI 304 stainless steel. The main objective of this study is to investigate the effect of significant process parameter on the surface roughness of machined AISI 304 stainless steel. Microstructural analysis has also been done for the machined surface.

\section{Materials and methods}

This investigation was carried out using ELECTRONICA- ELECTRAPLUS PS 50 ZNC (die-sinking type) with a servo head (constant gap) EDM machine. For this investigation, AISI 304 stainless steel and tungsten carbide electrode having diameter of $10 \mathrm{~mm}$ was taken as workpiece and electrode material respectively. SiC powder having a size of $\sim 20 \mu \mathrm{m}$ mixed into the kerosene oil in the electro discharge machining. The chemical composition of the AISI 304 stainless steel is shown in Table 1. The face centered central composite design (FCCCD) based response surface methodology (RSM) has been adopted for design the experimental layout. RSM is a group of mathematical and statistical techniques which are used for modeling and analysis of problems where the response is controlled by the input variables, and the objective is to develop a relationship amongst them (Montgomery, 2001). 33 experiments have been performed for this investigation. The process parameters are i) peak current $\left(\mathrm{I}_{\mathrm{p}}\right)$, ii) pulse on time $\left(\mathrm{T}_{\text {on }}\right)$, iii) gap voltage $\left(\mathrm{V}_{\mathrm{g}}\right)$, iv) duty cycle $(\mathrm{r})$, v) powder concentration $\left(\mathrm{P}_{\mathrm{C}}\right)$. The output parameter considered is surface roughness $\left(R_{a}\right) \mu \mathrm{m}$. The input parameters and their levels are listed in Table 2.

\section{Table 1}

Chemical Composition of AISI 304 stainless steel

\begin{tabular}{lllllllll}
\hline Element & $\mathrm{C}$ & $\mathrm{Mn}$ & $\mathrm{Si}$ & $\mathrm{P}$ & $\mathrm{S}$ & $\mathrm{Cr}$ & $\mathrm{Ni}$ & $\mathrm{Fe}$ \\
\hline$\%$ & 0.06 & 0.72 & 1.26 & 0.05 & 0.11 & 16.36 & 6.95 & Balance \\
\hline
\end{tabular}




\subsection{Experimental procedure}

The experimental layout and their results are tabulated in Table 3. Experiments are performed according to the designed matrix. The surface roughness of machined surface is measured by Talysurf (Model: Taylor Hobson, Surtronic 3+). Roughness is measured, in the transverse direction on the machined surface. The process is repeated three times and the average of three readings are noted as surface roughness value.

\section{Table 2}

Level values of input factor

\begin{tabular}{llll}
\hline Sl. No. & Factors & Levels & \\
\cline { 3 - 4 } & & Low $(-1)$ & High $(+1)$ \\
\hline 1 & $\mathrm{I}_{\mathrm{p}}(\mathrm{A})$ & 4 & 8 \\
2 & $\mathrm{~T}_{\text {on }}(\mu \mathrm{s})$ & 50 & 150 \\
3 & $\mathrm{~V}_{\mathrm{g}}(\mathrm{V})$ & 45 & 65 \\
4 & $\mathrm{r}(\%)$ & 55 & 65 \\
5 & $\mathrm{P}_{\mathrm{C}}(\mathrm{g} / \mathrm{l})$ & 0 & 10 \\
6 & Polarity & $+\mathrm{ve}$ & \\
7 & Machining Time $(\mathrm{min})$ & 10 & \\
8 & Dielectric Fluid & Kerosene Oil & \\
\hline
\end{tabular}

Table 3

Experimental layout and result of PMEDM performance

\begin{tabular}{lllllll}
\hline Exp. No & $\mathrm{I}_{\mathrm{p}}$ & $\mathrm{T}_{\text {on }}$ & $\mathrm{V}_{\mathrm{g}}$ & $\mathrm{r}$ & $\mathrm{P}_{\mathrm{C}}$ & $\mathrm{R}_{\mathrm{a}}$ \\
\hline 1 & 4 & 50 & 45 & 55 & 10 & 6.130 \\
2 & 8 & 50 & 45 & 55 & 0 & 10.130 \\
3 & 4 & 150 & 45 & 55 & 0 & 7.100 \\
4 & 8 & 150 & 45 & 55 & 10 & 9.860 \\
5 & 4 & 50 & 65 & 55 & 0 & 6.730 \\
6 & 8 & 50 & 65 & 55 & 10 & 7.870 \\
7 & 4 & 150 & 65 & 55 & 10 & 6.830 \\
8 & 8 & 150 & 65 & 55 & 0 & 9.940 \\
9 & 4 & 50 & 45 & 65 & 0 & 6.260 \\
10 & 8 & 50 & 45 & 65 & 10 & 9.330 \\
11 & 4 & 150 & 45 & 65 & 10 & 6.230 \\
12 & 8 & 150 & 45 & 65 & 0 & 9.760 \\
13 & 4 & 50 & 65 & 65 & 10 & 6.700 \\
14 & 8 & 50 & 65 & 65 & 0 & 9.660 \\
15 & 4 & 150 & 65 & 65 & 0 & 7.260 \\
16 & 8 & 150 & 65 & 65 & 10 & 8.400 \\
17 & 6 & 100 & 55 & 60 & 5 & 8.190 \\
18 & 6 & 100 & 55 & 60 & 5 & 8.360 \\
19 & 6 & 100 & 55 & 60 & 5 & 8.400 \\
20 & 6 & 100 & 55 & 60 & 5 & 8.260 \\
21 & 6 & 100 & 55 & 60 & 5 & 8.455 \\
22 & 6 & 100 & 55 & 60 & 5 & 8.360 \\
23 & 4 & 100 & 55 & 60 & 5 & 6.400 \\
24 & 8 & 100 & 55 & 60 & 5 & 9.160 \\
25 & 6 & 50 & 55 & 60 & 5 & 8.040 \\
26 & 6 & 150 & 55 & 60 & 5 & 8.560 \\
27 & 6 & 100 & 45 & 60 & 5 & 8.530 \\
28 & 6 & 100 & 65 & 60 & 5 & 8.280 \\
29 & 6 & 100 & 55 & 55 & 5 & 8.560 \\
30 & 6 & 100 & 55 & 65 & 5 & 8.600 \\
31 & 6 & 100 & 55 & 60 & 0 & 8.930 \\
32 & 6 & 100 & 55 & 60 & 10 & 7.660 \\
33 & 6 & 100 & 55 & 60 & 5 & 8.460 \\
\hline & & & & & & \\
\hline
\end{tabular}




\section{Result and discussion}

In Fig. 1 the mean response curve is presented showing the influence of input parameters $I_{P}, T_{o n}, V_{g}, \Gamma$ and $P_{C}$ on the performance of $R_{a}$. In this case, $I_{P}, T_{o n}$, and $\Gamma$ has a significant effect on $R_{a}$, and it is supported by Table 5 .

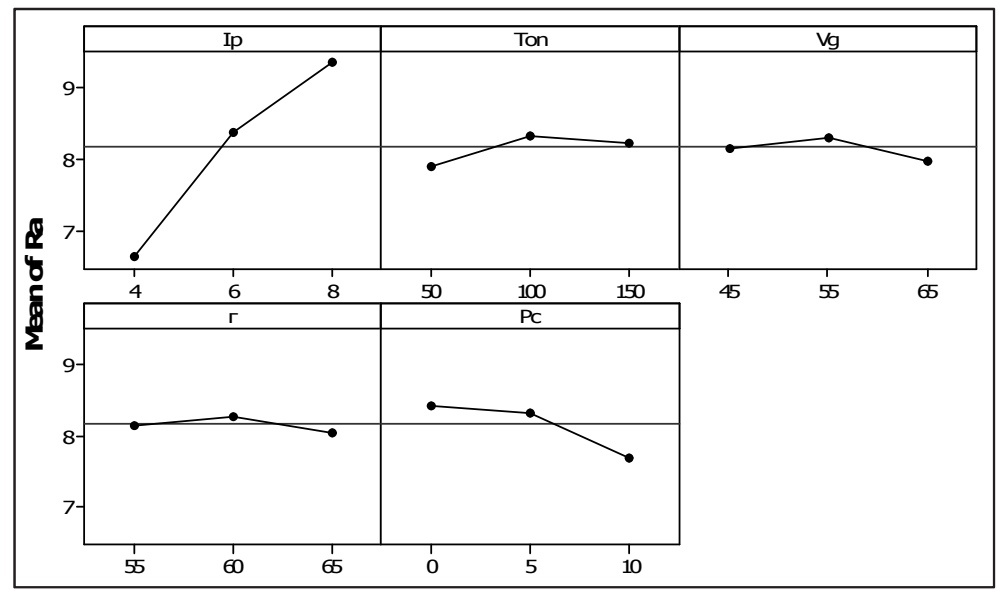

Fig. 1. Main effect plot for $R_{a}$

\section{Table 4}

ANOVA for $\mathrm{R}_{\mathrm{a}}$ (before elimination)

\begin{tabular}{|c|c|c|c|c|c|c|}
\hline Source & $\mathrm{DF}$ & Seq SS & Adj MS & $\mathrm{F}$ & $\mathrm{P}$ & $\%$ of contribution \\
\hline Regression & 20 & 41.2949 & 2.06475 & 101.25 & 0.000 & 99.41 \\
\hline Linear & 5 & 36.5380 & 0.49097 & 24.08 & 0.000 & 87.95 \\
\hline $\mathrm{I}_{\mathrm{P}}$ & 1 & 33.2656 & 1.84420 & 90.44 & 0.000 & 80.08 \\
\hline $\mathrm{T}_{\text {on }}$ & 1 & 0.5305 & 0.40225 & 19.73 & 0.001 & 1.27 \\
\hline $\mathrm{V}_{\mathrm{g}}$ & 1 & 0.1531 & 0.03864 & 1.89 & $0.194 \times$ & 0.36 \\
\hline$\Gamma$ & 1 & 0.0501 & 0.16369 & 8.03 & 0.015 & 0.12 \\
\hline $\mathrm{P}_{\mathrm{C}}$ & 1 & 2.5388 & 0.00343 & 0.17 & $0.689 \times$ & 6.11 \\
\hline Square & 5 & 1.4531 & 0.29061 & 14.25 & 0.000 & 3.49 \\
\hline $\mathrm{I}_{\mathrm{P}} \times \mathrm{I}_{\mathrm{P}}$ & 1 & 1.2459 & 0.76983 & 37.75 & 0.000 & 2.99 \\
\hline $\mathrm{T}_{\text {on }} \times \mathrm{T}_{\text {on }}$ & 1 & 0.0192 & 0.00377 & 0.18 & $0.675 \times$ & 0.04 \\
\hline$V_{g} \times V_{g}$ & 1 & 0.0448 & 0.01069 & 0.52 & $0.483 \times$ & 0.10 \\
\hline$\Gamma \times \Gamma$ & 1 & 0.1384 & 0.14289 & 7.01 & $0.021 \times$ & 0.33 \\
\hline $\mathrm{Pc} \times \mathrm{Pc}$ & 1 & 0.0048 & 0.00479 & 0.24 & $0.637 \times$ & 0.01 \\
\hline Interaction & 10 & 3.3038 & 0.33038 & 16.20 & 0.000 & 7.95 \\
\hline $\mathrm{I}_{\mathrm{P}} \times \mathrm{T}_{\mathrm{on}}$ & 1 & 0.0248 & 0.02481 & 1.22 & $0.292 \times$ & 0.06 \\
\hline $\mathrm{I}_{\mathrm{P}} \times \mathrm{V}_{\mathrm{g}}$ & 1 & 1.5688 & 1.56876 & 76.93 & 0.000 & 3.78 \\
\hline $\mathrm{I}_{P} \times \Gamma$ & 1 & 0.0060 & 0.00601 & 0.29 & $0.597 \times$ & 0.01 \\
\hline $\mathrm{I}_{\mathrm{P}} \times \mathrm{Pc}$ & 1 & 0.4128 & 0.41281 & 20.24 & 0.001 & 0.99 \\
\hline $\mathrm{T}_{\text {on }} \times \mathrm{Vg}$ & 1 & 0.0086 & 0.00856 & 0.42 & $0.529 \times$ & 0.02 \\
\hline $\mathrm{T}_{\mathrm{on}} \times \Gamma$ & 1 & 0.6281 & 0.62806 & 30.80 & 0.000 & 1.51 \\
\hline $\mathrm{T}_{\mathrm{on}} \times \mathrm{Pc}$ & 1 & 0.0000 & 0.00001 & 0.00 & $0.986 \times$ & 0.00 \\
\hline $\mathrm{V}_{\mathrm{g}} \times \Gamma$ & 1 & 0.3278 & 0.32776 & 16.07 & 0.002 & 0.79 \\
\hline $\mathrm{V}_{\mathrm{g}} \times \mathrm{Pc}$ & 1 & 0.2730 & 0.27301 & 13.39 & 0.003 & 0.66 \\
\hline$\Gamma \times \mathrm{Pc}$ & 1 & 0.0541 & 0.05406 & 2.65 & $0.129 \times$ & 0.13 \\
\hline Residual Error & 12 & 0.2447 & 0.02039 & & & 0.59 \\
\hline Lack-of-Fit & 6 & 0.1854 & 0.03089 & 3.12 & $0.096 \times$ & 0.45 \\
\hline Pure Error & 6 & 0.0594 & 0.00989 & & & 0.14 \\
\hline Total & 32 & 41.5396 & & & & \\
\hline $\mathrm{S}=0.142802 \mathrm{R}$ & 41 & $\mathrm{Sq}(\operatorname{adj})=$ & & & & \\
\hline
\end{tabular}


From the main effect plot, it is seen that when $I_{P}$ increases from $4 \mathrm{~A}$ to $6 \mathrm{~A}, \mathrm{R}_{\mathrm{a}}$ increases by $1.83 \mu \mathrm{m}$ and $1.083 \mu \mathrm{m}$ increases when IP increases from $6 \mathrm{~A}$ to $8 \mathrm{~A}$. When $\mathrm{T}_{\text {on }}$ increases from $50 \mu$ s to $100 \mu \mathrm{s} \mathrm{R}_{\mathrm{a}}$ increases upto $0.46 \mu \mathrm{m}$ and then decreases upto $0.085 \mu \mathrm{m}$ when $\mathrm{T}_{\text {on }}$ increases from $100 \mu \mathrm{s}$ to $150 \mu \mathrm{s}$. Gap voltage increases from $45 \mathrm{~V}$ to $65 \mathrm{~V}, \mathrm{R}_{\mathrm{a}}$ decreases by $0.25 \mu \mathrm{m}$ having a maximum $\mathrm{R}_{\mathrm{a}}$ of $8.33 \mu \mathrm{m}$ at $55 \mathrm{~V}$. Duty cycle increases from $55 \%$ to $65 \%, \mathrm{R}_{\mathrm{a}}$ drcreases up to $0.167 \mu \mathrm{m}$ with a maximum $\mathrm{R}_{\mathrm{a}}$ of 8.25 $\mu \mathrm{m}$ at $60 \%$. When $\mathrm{SiC}$ powder is added up to $10 \mathrm{~g} / 1, \mathrm{R}_{\mathrm{a}}$ gradually decreases up to $0.83 \mu \mathrm{m}$. Table 4 shows the ANOVA for $\mathrm{R}_{\mathrm{a}}$ with the percentage of contribution of each parameter and their interactions. It shows that the process parameter such as peak current, pulse on time, duty cycle, square term of peak current and interaction term of peak current $\times$ gap voltage, peak current $\times$ powder concentration, pulse on time $\times$ duty cycle, gap voltage $\times$ duty cycle, gap voltage $\times$ powder concentration have significant effects on the $\mathrm{R}_{\mathrm{a}}$. This table shows that peak current is the most efficient factor for the $\mathrm{R}_{\mathrm{a}}$. It has $80.08 \%$ contribution followed by powder concentration, pulse on time, gap voltage and duty cycle having a percentage of contribution of $6.11 \%, 1.27 \%, 0.36 \%$ and $0.12 \%$ respectively. The coefficient of determination $\left(\mathrm{R}^{2}\right)$ and adjusted $\left(\mathrm{R}^{2}\right)$ values are found to be $99.41 \%$ and $98.43 \%$, respectively. Lack of fit is not significant for Ra. Table 5 shows the ANOVA table for $\mathrm{R}_{\mathrm{a}}$ after eliminating all the insignificant terms. The truncated model possesses lower $R^{2}$ than the full quadratic model $\left(R^{2}=99.15 \%\right)$. This exhibits the significance of relationship between the response and the machining parameters for $\mathrm{R}_{\mathrm{a}}$.

\section{Table 5}

ANOVA table for $\mathrm{R}_{\mathrm{a}}$ (after elimination)

\begin{tabular}{lllllll}
\hline Source & $\mathrm{DF}$ & $\mathrm{Seq} S \mathrm{~S}$ & Adj MS & $\mathrm{F}$ & $\mathrm{P}$ & \% of contribution \\
\hline Regression & 12 & 41.1856 & 3.43213 & 193.89 & 0.000 & 99.14 \\
\hline Linear & 5 & 36.5380 & 1.24532 & 70.35 & 0.000 & 87.95 \\
$\mathrm{I}_{\mathrm{P}}$ & 1 & 33.2656 & 3.59757 & 203.23 & 0.000 & 80.08 \\
$\mathrm{~T}_{\mathrm{on}}$ & 1 & 0.5305 & 0.71760 & 40.54 & 0.000 & 1.27 \\
$\mathrm{~V}_{\mathrm{g}}$ & 1 & 0.1531 & 0.05652 & 3.19 & $0.089 \times$ & 0.36 \\
$\Gamma$ & 1 & 0.0501 & 0.21986 & 12.42 & 0.002 & 0.12 \\
$\mathrm{P}_{\mathrm{C}}$ & 1 & 2.5388 & 0.27115 & 15.32 & 0.001 & 6.11 \\
\hline $\mathrm{Square}$ & 2 & 1.4372 & 0.71859 & 40.59 & 0.000 & 3.45 \\
$\mathrm{I}_{\mathrm{P}} \times \mathrm{I}_{\mathrm{P}}$ & 1 & 1.2459 & 1.12712 & 63.67 & 0.000 & 2.99 \\
$\Gamma \times \Gamma$ & 1 & 0.1913 & 0.19130 & 10.81 & 0.004 & 0.46 \\
\hline Interaction & 5 & 3.2104 & 0.64208 & 36.27 & 0.000 & 7.72 \\
\hline $\mathrm{I}_{\mathrm{P}} \times \mathrm{V}_{\mathrm{g}}$ & 1 & 1.5688 & 1.56876 & 88.62 & 0.000 & 3.77 \\
$\mathrm{I}_{\mathrm{P}} \times \mathrm{Pc}$ & 1 & 0.4128 & 0.41281 & 23.32 & 0.000 & 0.99 \\
\hline $\mathrm{T}_{\text {on }} \times \Gamma$ & 1 & 0.6281 & 0.62806 & 35.48 & 0.000 & 1.51 \\
$\mathrm{~V}_{\mathrm{g}} \times \Gamma$ & 1 & 0.3278 & 0.32776 & 18.52 & 0.000 & 0.78 \\
\hline $\mathrm{V}_{\mathrm{g}} \times \mathrm{Pc}$ & 1 & 0.2730 & 0.27301 & 15.42 & 0.001 & 0.65 \\
\hline Residual Error & 20 & 0.3540 & 0.01770 & & & 0.85 \\
\hline Lack-of-Fit & 14 & 0.2947 & 0.02105 & 2.13 & $0.181 \times$ & 0.70 \\
\hline Pure Error & 6 & 0.0594 & 0.00989 & & & 0.14 \\
\hline Total & 32 & 41.5396 & & & & \\
\hline $\mathrm{S}=0.133047$ & $\mathrm{R}-\mathrm{Sq}=99.15 \%$ & $\mathrm{R}-\mathrm{Sq}(\mathrm{adj})=98.64 \%$ & & & \\
\hline
\end{tabular}

The model acquired from the regression analysis for $\mathrm{R}_{\mathrm{a}}$ shows the influence of linear, square and interaction terms as shown the Eq. (1).

$$
\begin{aligned}
& \mathrm{R}_{\mathrm{a}}=32.2769+3.3209 \times \mathrm{I}_{\mathrm{P}}+0.0510 \times \mathrm{T}_{\text {on }}-0.0740 \times \mathrm{V}_{\mathrm{g}}-1.2091 \times \Gamma+0.1650 \times \mathrm{P}_{\mathrm{C}}- \\
& 0.1416 \times \mathrm{I}_{\mathrm{P}}{ }^{2}+0.0093 \times \Gamma^{2}-0.0157 \times \mathrm{I}_{\mathrm{P}} \times \mathrm{V}_{\mathrm{g}}-0.0161 \times \mathrm{I}_{\mathrm{P}} \times \mathrm{P}_{\mathrm{C}}-0.0008 \times \mathrm{T}_{\text {on }} \times \Gamma- \\
& 0.0029 \times \mathrm{V}_{\mathrm{g}} \times \Gamma-0.0026 \times \mathrm{V}_{\mathrm{g}} \times \mathrm{P}_{\mathrm{C}}
\end{aligned}
$$

Fig. 2 represents the contour and $3 \mathrm{D}$ response plot on the $\mathrm{I}_{\mathrm{P}}$ and $\mathrm{T}_{\text {on }}$ at a constant level of $\mathrm{V}_{\mathrm{g}}, \mathrm{I}$, and $\mathrm{P}_{\mathrm{C}}$. It is seen that $R_{a}$ increases with the increases of $I_{P}$ and $T_{\text {on. }} R_{a}$ is minimum at lower value of $I_{P}(4 A)$ and $\mathrm{T}_{\text {on }}(50 \mu \mathrm{s})$. It happens because with the increase of discharge current the discharge energy density and impulsive force increases leading to a deeper and larger crater, hence surface roughness increases. With 
the increase of $\mathrm{T}_{\text {on }}, \mathrm{R}_{\mathrm{a}}$ increases. It happens because an increase in pulse on time the plasma channel in between the tool-worlpiece interface expands which decreases the discharge energy density and impulsive force. For this molten metal cannot be removed properly from the channel resulting increase in $R_{a}$.
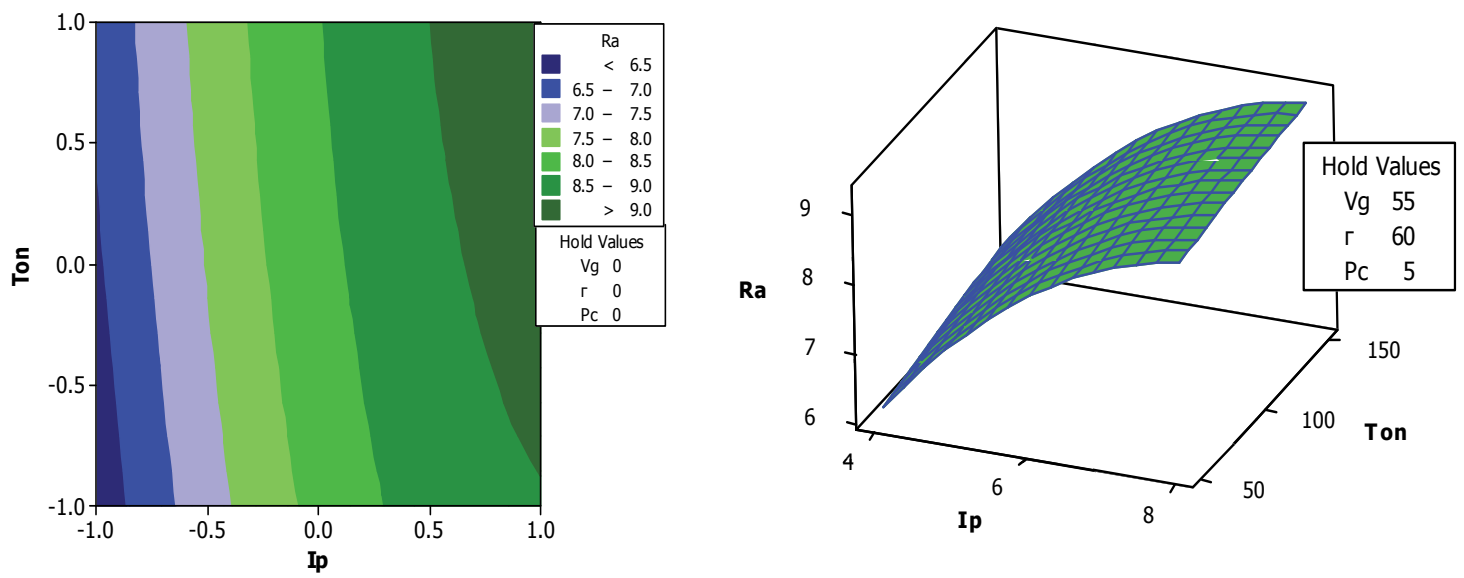

Fig. 2. Contour and response surface plot depicting the effect of $I_{P}$ and $T_{\text {on }}$ on $R_{a}$
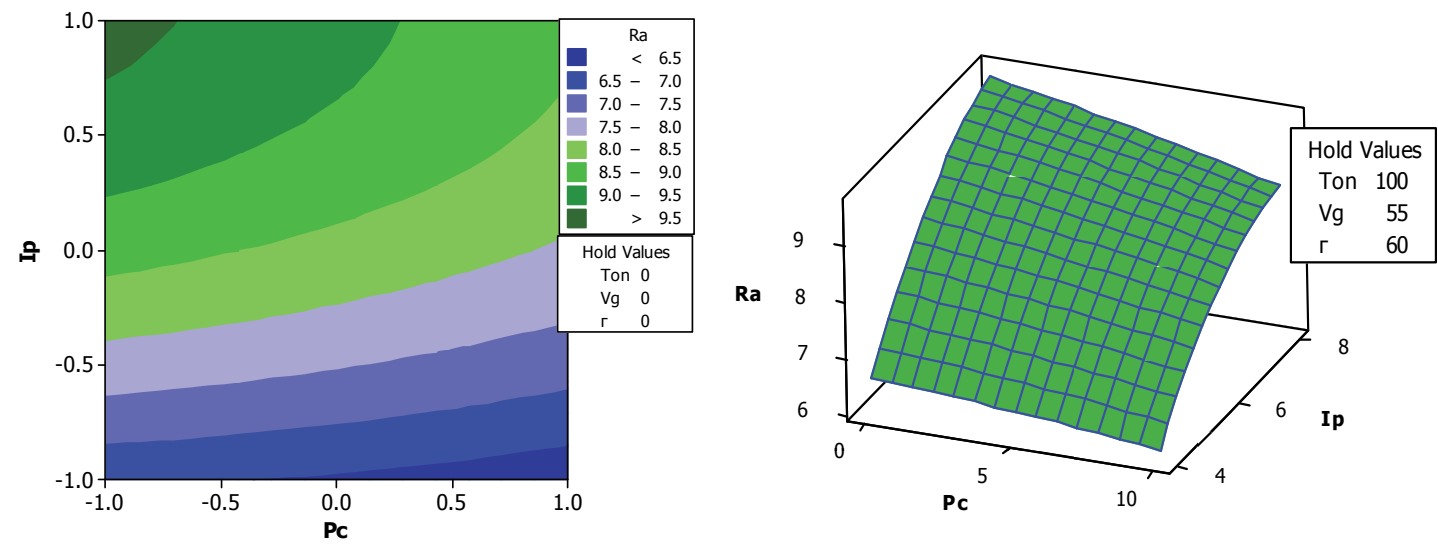

Fig. 3. Contour and response surface plot depicting the effect of $P_{C}$ and $I_{P}$ on $R_{a}$

Fig. 3 represents the contour and $3 \mathrm{D}$ response plot on the $\mathrm{P}_{\mathrm{C}}$ and $\mathrm{I}_{\mathrm{P}}$ at a constant level of $\mathrm{V}_{\mathrm{g}}, \mathrm{I}$, and $\mathrm{T}_{\text {on. }}$ It is seen that $R_{a}$ increases with the increases of $I_{P}$ and decreases with the increase of powder concentration. $R_{a}$ is minimum at lower value of $I_{P}(4 A)$ and higher value of $P_{C}(10 \mathrm{~g} / \mathrm{l})$. A significant decrease in $\mathrm{R}_{\mathrm{a}}$ is observed with the addition of powder concentration in the dielectric. When powder particle are mixed into the dielectric the plasma channel get enlarged and widened. So the discharge energy is distributed among the powder particle over a large area. As a result the large and shallow craters are generated on the workpiece surface (Fong and Chen, 2005). Along with this, the molten metal is not heavily compressed by the plasma channel and the gas babble. This condition reduces the entrapping of gas in the machining cavity. Hence the surface turn out to be less concave, smooth and uniform (Tzeng and Lee, 2001).

\subsection{Microstructural analysis}

The SEM image of the machined surface are taken with 500X magnification. Fig. 4, Fig. 5, Fig. 6 shows the SEM images of AISI 304 at various level of Ip. It is seen from the figure that the existance of cracks are limited in the white layer. This layer consists of cracks, micro cracks, pores and globules. This layer is mainly composed of retained austenite, martensite, and some dissolved carbide. 


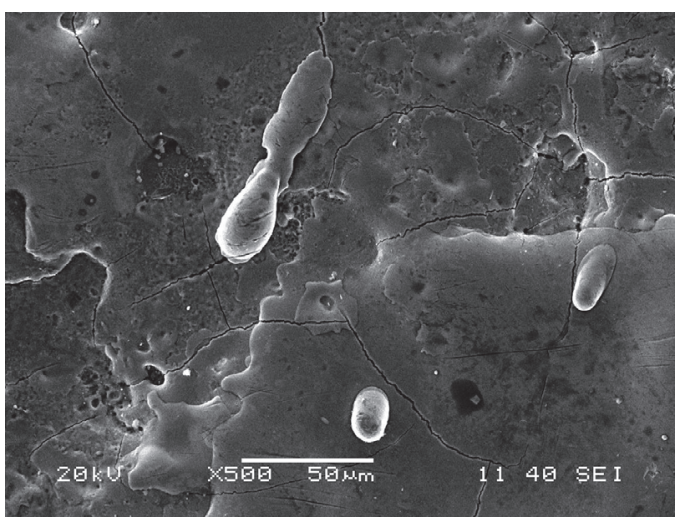

Fig. 4. Surface characteristics at $\mathrm{I}_{\mathrm{P}}=4 \mathrm{~A}, \mathrm{~V}=55 \mathrm{~V}$, $\mathrm{T}_{\text {on }}=100 \mu \mathrm{s}, \mathrm{r}=60 \%, \mathrm{P}_{\mathrm{C}}=5 \mathrm{~g} / 1$

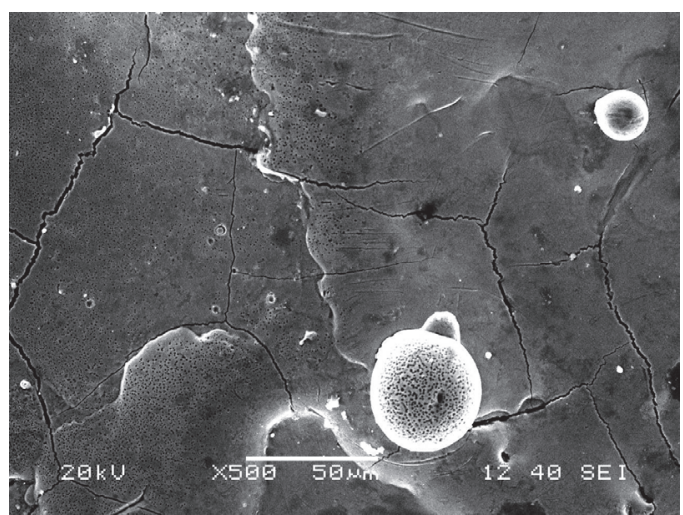

Fig. 5. Surface characteristics at $I_{P}=6 A, V=55 V$, $\mathrm{T}_{\mathrm{on}}=100 \mu \mathrm{s}, \mathrm{r}=60 \%, \mathrm{P}_{\mathrm{C}}=5 \mathrm{~g} / 1$

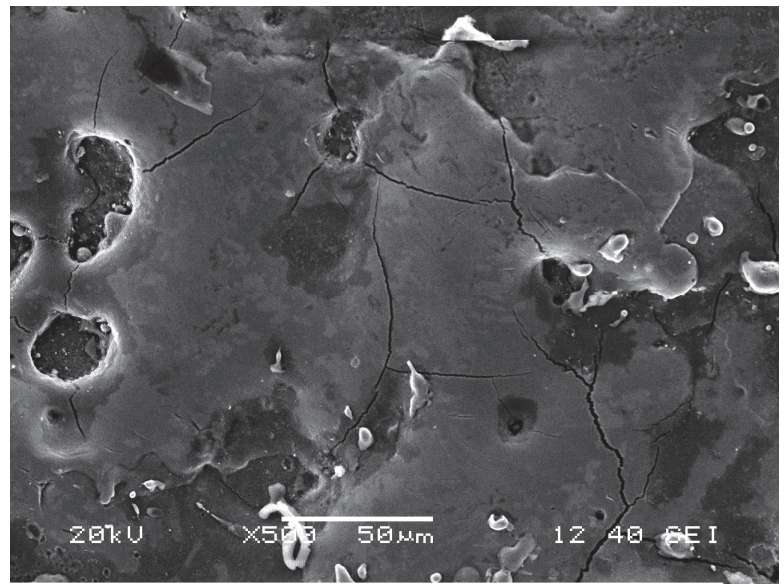

Fig. 6. Surface characteristics at $\mathrm{I}_{\mathrm{P}}=8 \mathrm{~A}$, $\mathrm{V}=55 \mathrm{~V}, \mathrm{~T}_{\text {on }}=100 \mu \mathrm{s}, \mathrm{r}=60 \%, \mathrm{P}_{\mathrm{C}}=5 \mathrm{~g} / 1$

Surface cracks are clearly visible in the microstructures. From the SEM images, it is seen that the machined surface has complex exterior such as craters, globules, pores because of the rapid heating and quenching. The formation of surface cracks is credited to the differentials of residual/ contraction stress within the white layer. When the contraction stress exceeds the material's ultimate tensile stress, the surface crack develops. It is seen that with the increase of peak current the surface irregularities increases leads increase in surface roughness.

\section{Conclusions}

In this study the influence of most significant parameter on the surface roughness has been studied for AISI 304 stainless steel. RSM based face centered central composite design (FCCCD) has been adopted to conduct the experiment. A full quadratic mathematical model of process parameters which have the significant effect on $\mathrm{R}_{\mathrm{a}}$ has been developed. The input factor such as peak current, pulse on time, duty cycle and powder concentration have a significant effect on the $R_{a}$. $R_{a}$ should keep as minimum as possible. For the best setting of $\mathrm{R}_{\mathrm{a}}$ peak current of $4 \mathrm{~A}$, pulse on time of $50 \mu \mathrm{s}$, gap voltage of $65 \mathrm{~V}$, duty cycle of $65 \%$ and $10 \mathrm{~g} / 1 \mathrm{SiC}$ powder concentration should be considered which yields the best value of $\mathrm{R}_{\mathrm{a}}$ of $6.7 \mu \mathrm{m}$. The developed mathematical model for $\mathrm{R}_{\mathrm{a}}$ can be effectively employed for optimal selection of PMEDM process parameter to achieve good surface finish of AISI 304 stainless steel. In the SEM image surface cracks, globules, pores are observed. With the increases of peak current the surface irregularities increases. 


\section{References}

Bhaumik, M., \& Maity, K. P. (2014). Study the effect of Tungsten Carbide Electrode on stainless steel (AISI 304) material in die sinking EDM. Journal of Material Science and Mechanical Engineering (JMSME), 1(1), 1-6.

Bhattacharya, A., Batish, A., \& Kumar, N. (2013). Surface characterization and material migration during surface modification of die steels with silicon, graphite and tungsten powder in EDM process. Journal of Mechanical Science and Technology, 27(1), 133-140.

Choudhary, S., Kant, K., \& Saini, P. (2013). Analysis of MRR and SR with Different Electrode for SS 316 on Die-Sinking EDM using Taguchi Technique. Global Journal of Researches in Engineering Mechanical and Mechanics Engineering, 13(3), 14-21.

Fong, T.Y., \& Chen, F.C. (2005). Investigation into some surface characteristics of electrical discharge machined SKD-11 using powder suspension dDielectric. Oil, Journal of Materials Processing Technology, 170(1), 385-391.

Habib, S. S. (2009). Study of the parameters in electrical discharge machining through response surface methodology approach. Applied Mathematical Modelling, 33(12), 4397-4407.

Kansal, H. K., Singh, S., \& Kumar, P. (2005). Parametric optimization of powder mixed electrical discharge machining by response surface methodology. Journal of Materials Processing Technology, 169(3), 427-436.

Kansal, H. K., Singh, S., \& Kumar, P. (2007). Effect of Silicon Powder Mixed EDM on Machining Rate of AISI D2 Die Steel. Journal of Materials Processing Technology, 9(1), 14-22.

Kumar, A., Maheshwari, S., Sharma, C., \& Beri, N. (2010). Research developments in additives mixed electrical discharge machining (AEDM): a state of art review. Materials and Manufacturing processes, 25(10), 1166-1180.

Kumar, S., \& Batra, U. (2012). Surface modification of die steel materials by EDM method using tungsten powder-mixed dielectric. Journal of Manufacturing Processes, 14(1), 35-40.

Luis, C.J., Puertas, I., \& Villa, G. (2005). Material removal rate and electrode wear study on the EDM of silicon carbide. Journal of Materials Processing Technology, 164, 889-896.

Pandey, A., \& Singh, S. (2010). Current research trends in variants of Electrical Discharge Machining: A review. International Journal of Engineering Science and Technology, 2(6), 2172-2191.

Mohanty, A., Talla, G., \& Gangopadhyay, S. (2014). Experimental investigation and analysis of EDM characteristics of Inconel 825. Materials and Manufacturing Processes, 29(5), 540-549.

Montgomery, D.C. (2001). Design and Analysis of Experiments. $5^{\text {th }}$ ed., John Wiley and Sons, Inc., NY.

Pradhan, M. K. (2013). Estimating the effect of process parameters on MRR, TWR and radial overcut of EDMed AISI D2 tool steel by RSM and GRA coupled with PCA. The International Journal of Advanced Manufacturing Technology, 68(1-4), 591-605.

Rajagopal, S. P., Ganesh, V., Lanjewar, A. V., \& Sankar, M. R. (2013). Past and Current Status of Hybrid Electric Discharge Machining (H-EDM) Processes. Advanced Materials Manufacturing \& Characterization, 3(1), 111-118.

Singh, S., \& Bhardwaj, A. (2011). Review to EDM by using water and powder-mixed dielectric fluid. Journal of Minerals \& Materials Characterization \& Engineering, 10(2), 199-230.

Singh, B., Kumar, J., \& Kumar, S. (2015). Influences of process parameters on MRR improvement in simple and powder-mixed EDM of AA6061/10\% SiC composite. Materials and Manufacturing Processes, 30(3), 303-312.

Tzeng, Y. F., \& Lee, C. Y. (2001). Effects of powder characteristics on electrodischarge machining efficiency. The International Journal of advanced manufacturing technology, 17(8), 586-592.

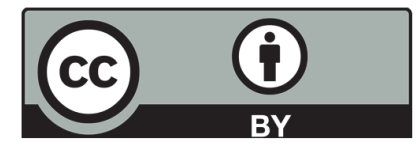

(C) 2017 by the authors; licensee Growing Science, Canada. This is an open access article distributed under the terms and conditions of the Creative Commons Attribution (CC-BY) license (http://creativecommons.org/licenses/by/4.0/). 